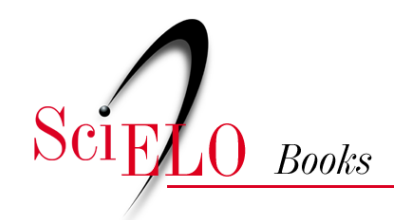

EDUFU

\title{
A posição do espectador perspectivas pedagógicas
}

\author{
Flávio Desgranges
}

\section{SciELO Books / SciELO Livros / SciELO Libros}

DESGRANGES, F. A posição do espectador: perspectivas pedagógicas. In: FLORENTINO, A., and TELLES, N., eds. Cartografias do ensino do teatro [online]. Uberlândia: EDUFU, 2008, pp. 85-94. ISBN 978-85-7078-518-3. https://doi.org/10.7476/9788570785183.0009.

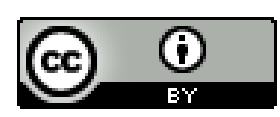

All the contents of this work, except where otherwise noted, is licensed under a Creative Commons Attribution 4.0 International license.

Todo o conteúdo deste trabalho, exceto quando houver ressalva, é publicado sob a licença Creative Commons Atribição 4.0.

Todo el contenido de esta obra, excepto donde se indique lo contrario, está bajo licencia de la licencia $\underline{\text { Creative Commons }}$ Reconocimento 4.0. 


\section{A POSIÇÃO DO ESPECTADOR: PERSPECTIVAS PEDAGÓGICAS}

Flávio Desgranges

O pensamento a respeito da posição do espectador em sua relação com a obra teatral permite que se apontem enfoques diversos e, quem sabe, complementares acerca das perspectivas pedagógicas que podem ser traçadas a partir deste encontro entre aquele que age em cena e aquele que observa da sala. Alguns aspectos podem ser destacados com vistas ao desdobramento da questão, tomando por diferentes ângulos esta pedagogia do espectador: 1) pode-se tomar a atividade proposta ao espectador como sendo por si pedagógica, apoiando-se, por exemplo, na máxima benjaminiana ${ }^{1}$, que aponta que na própria experiência artística reside seu potencial educacional, pois este lhe é inerente; 2) um outro feixe reflexivo se descortina ampliando a questão, ao se reconhecer o jogo de linguagem formulado pelo artista nas provocações estéticas que faz ao espectador, como proposições pedagógicas; 3 ) pode-se ainda abordar esta relação entre palco e platéia sob o âmbito da formação de espectadores apontando a relevância de um público teatral especializado, além dos procedimentos pedagógicos que podem ser adotados tendo em vista a dinamização da recepção teatral e a criação do gosto por esta arte.

Trataremos, aqui, o assunto tendo em vista especialmente o último dos aspectos ressaltados, traçando possíveis desdobramentos para a formulação de uma pedagogia do espectador ressaltando a pertinência da questão e os procedimentos pedagógicos a serem adotados no âmbito da formação de espectadores teatrais. Contudo, ao enfocarmos o teatro épico de Bertolt Brecht, serão abordados também alguns dos aspectos citados no item dois, dando conta, ainda que de maneira breve, de como as proposições estéticas formuladas pelo artista teatral podem ser tomadas como propostas pedagógicas.

\section{A formação de espectadores}

As pesquisas acerca da importância da formação de espectadores vêm tendo grande desenvolvimento nos últimos anos em todo o mundo. São dois os fatores preponderantes que sustentam estas investigações, e apontam para a necessidade

\footnotetext{
1 "A arte é educadora enquanto arte, não enquanto arte educadora", Walter Benjamin [1892-
} 1940], filósofo alemão. 
cada vez maior de implementação de práticas de formação: a necessária participação dos espectadores no desenvolvimento da arte teatral, o que sugere a efetiva atuação de um público teatral interessado nos próprios rumos desta arte; e a formação crítica do indivíduo contemporâneo que, numa sociedade espetacularizada, vê-se exposto cotidianamente a uma enxurrada de signos, diante dos os quais precisa encontrar-se apto para dialogar e produzir sentidos próprios.

Assim, o primeiro dos aspectos citados diz respeito à importância de que haja espectadores interessados em ver e debater teatro, já que não há desenvolvimento da arte teatral que possa se dar sem a efetiva participação dos espectadores. Não existe teatro sem platéia e a importância da presença do espectador nele precisa ser vista não somente por uma razão econômica, de sustentação financeira das produções. É evidente que o fator econômico é vital e não pode ser esquecido, até porque o preço do ingresso torna o acesso inviável, excluindo das salas uma parcela do público que talvez fosse a mais interessada. Como um livro que só existe quando alguém o abre, o teatro não existe sem a presença deste outro com o qual ele dialoga sobre o mundo e sobre si mesmo. Sem espectadores interessados neste debate, o teatro perde conexão com a realidade a que se propõe refletir e, sem a referência deste outro, o seu discurso se torna ensimesmado, desencontrado, estéril. Não há evolução ou transformação do teatro que se dê, portanto, sem a efetiva participação dos espectadores.

O olhar do observador sobre o espetáculo sustenta o próprio jogo do teatro. A necessidade de companheiros de jogo, companheiros de criação, anima o movimento de formação de espectadores. Uma pedagogia do espectador se justifica, assim, pela necessária presença de um outro que exija diálogo, pela fundamental participação criativa deste jogador no evento teatral; participação que se efetiva na sua resposta às proposições cênicas, na sua capacidade de elaborar os signos trazidos à cena e de formular um juízo próprio dos sentidos.

O público participativo é aquele que, durante o ato da representação, exige que cada instante do espetáculo não seja gratuito, o que não significa que seja necessário, pois, se manifestar ou intervir diretamente para participar do evento. A sua presença se efetiva na cumplicidade que ele estabelece com o palco, na vontade de compactuar com o evento, na atenção às proposições cênicas, na atitude desperta, no olhar aceso. Este espectador crítico, exigente e participativo é aliado fundamental nos diálogos travados acerca dos rumos da arte teatral.

O outro fator relevante para se pensar uma pedagogia do espectador, em nossos dias, diz respeito à espetacularização da sociedade, ocasionada pela proliferação de meios de comunicação de massa. Esses meios condicionam a sensibilidade e a percepção dos indivíduos contemporâneos, e indicam a necessidade de uma formação reflexiva do observador, visando a sua aptidão tanto para perceber os recursos espetaculares utilizados, quanto para analisar a produção de sentidos veiculada por estes canais de comunicação.

Em uma sociedade baseada na espetacularidade dos acontecimentos e apoiada na indústria moderna, que "não é fortuitamente ou superficialmente espetacular, ela é fundamentalmente 'espetacularista”, em que o espetáculo é “o sol que não se esconde

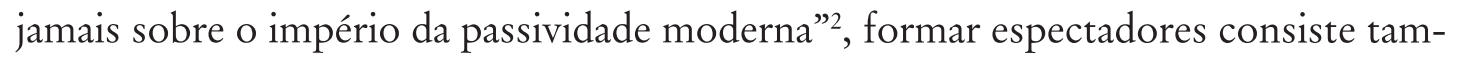

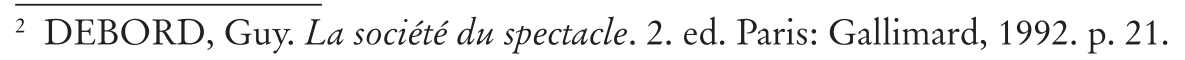


bém em estimular os indivíduos (de todas as idades) a ocupar o seu lugar não somente no teatro, mas no mundo. Educar o espectador para que não se contente em ser apenas o receptáculo de um discurso que lhe proponha um silêncio passivo. A formação do olhar e a aquisição de instrumentos lingüísticos sensibilizam o espectador para o diálogo que se estabelece nas salas de espetáculo, além de estimulá-lo para enfrentar o duelo que se trava no dia-a-dia. O olhar armado busca uma interpretação aguda dos signos utilizados nos espetáculos diários, na propaganda, nos noticiários, nos programas eleitorais, ou mesmo nas produções da cultura de massa. Com um senso crítico apurado, este consumidor-espectador, eleitor-espectador, cidadão-espectador procura estabelecer novas relações com o entorno e com as diferentes manifestações espetaculares que buscam retratá-lo.

Se nesta sociedade "a linguagem do espetáculo é constituída pelos signos da produção reinante" ${ }^{\text {, }}$ tomar conhecimento dos mecanismos que envolvem uma encenação, desvendar e apreender a lógica da teatralidade significa conquistar instrumentos que viabilizem a reflexão acerca dos procedimentos utilizados nas diferentes produções espetaculares. $\mathrm{O}$ espectador especialista se encontra em condições de decodificar os signos e de questionar os significados produzidos, seja no palco ou fora dele.

A formação de espectadores se justifica também pela urgência de uma tomada de posição crítica frente às representações dominantes, pela necessária aptidão do indivíduo-espectador para questionar os procedimentos e desmistificar os códigos espetaculares hegemônicos.

\section{Viabilizar o acesso do espectador ao teatro. Duplo acesso}

O despertar do interesse do espectador não pode acontecer sem a implementação de medidas e procedimentos que tornem viáveis o seu acesso ao teatro. $\mathrm{Na}$ verdade, duplo acesso: o físico e o lingüístico. Ou seja, tanto a possibilidade do indivíduo freqüentar os espetáculos quanto a sua aptidão para a leitura das obras teatrais. Antes disso, é fato, torna-se necessário que tenhamos boas condições de produção para um oferecimento quantitativo e qualitativo de espetáculos teatrais. No entanto, não é suficiente ter oferta de peças em cartaz, é preciso mediar este encontro entre palco e platéia. Primeiramente, é preciso criar condições para o espectador ir ao teatro, o que envolve uma série de medidas para favorecer a freqüentação, tais como: divulgação competente das peças em cartaz, que atinja públicos de diversas regiões e classes sociais; promoções e incentivos que viabilizem financeiramente o acesso das diferentes faixas de público; condições de segurança; rede de transportes eficiente; e tantas outras atitudes de apoio e incentivo que visem, em última instância, a colocar o espectador diante do espetáculo (ou vice-versa). O acesso ao teatro, porém, não se resume a possibilitar a ida às salas (ou a levar espetáculos itinerantes a regiões menos favorecidas). Formar espectadores não se restringe a apoiar e estimular a freqüentação, é preciso preparar e estimular o espectador para um rico e intenso diálogo com a obra, criando, assim, o desejo pela experiência artística.

Portanto, a pedagogia do espectador, no âmbito da formação, está calcada fundamentalmente nos procedimentos adotados para criar o gosto pelo debate es-

${ }^{3}$ DEBORD, 1992, p. 18. 
tético, para estimular no espectador o desejo de lançar um olhar particular à peça teatral, de empreender uma pesquisa pessoal na interpretação que se faz da obra, despertando o seu interesse para uma batalha que se trava nos campos da linguagem. Assim, contribui-se para formar espectadores que estejam aptos para decifrar os signos propostos, para elaborar um percurso próprio no ato de leitura da encenação, colocando em jogo sua subjetividade, seu ponto de vista, partindo de suas experiências, da posição, do lugar que ocupa na sociedade. A experiência teatral é única e cada espectador descobrirá a sua forma de abordar a obra e de estar disponível para o evento.

Figura chave nas reflexões traçadas entre teatro e educação, Brecht afirmava que a leitura crítica, a capacidade de compreensão de uma obra de arte, no entanto, pode e precisa ser trabalhada. A capacidade de elaboração estética é uma conquista e não somente um talento natural.

É uma opinião antiga e fundamental que uma obra de arte deve influenciar todas as pessoas, independente da idade, status ou educação [...]. Todas as pessoas podem entender e sentir prazer com uma obra de arte porque todas têm algo artístico dentro de si [...]. Existem muitos artistas dispostos a não fazer arte apenas para um pequeno círculo de iniciados, que querem criar para o povo. Isso soa democrático, mas, na minha opinião, não é totalmente democrático. Democrático é transformar o pequeno círculo de iniciados em um grande círculo de iniciados. Pois a arte necessita de conhecimentos. A observação da arte só poderá levar a um prazer verdadeiro, se houver uma arte da observação. Assim como é verdade que em todo homem existe um artista, que o homem é o mais artista dentre todos os animais, também é certo que essa inclinação pode ser desenvolvida ou perecer. Subjaz à arte um saber que é um saber conquistado através do trabalho ${ }^{4}$.

A especialização do espectador se efetiva na sua aquisição de conhecimentos de teatro, o prazer que ele experimenta em uma encenação se intensifica com a sua apreensão da linguagem teatral. O prazer estético, portanto, solicita aprendizado. A arte do espectador é um saber que se conquista com trabalho.

Familiarizado com os códigos teatrais, este espectador iniciado descobre pistas próprias de como se relacionar com a obra, percebendo-se no ato da recepção capaz de dar unidade ao conjunto de signos utilizados na encenação e de estabelecer conexões entre os elementos apresentados e a realidade exterior. A conquista da linguagem teatral propicia ao espectador uma atitude não submissa diante do fato narrado e das opções cênicas propostas. Conhecendo os signos que vêm sendo estabelecidos ao longo da história do teatro, bem como o funcionamento dos mecanismos utilizados em uma encenação, e os efeitos que produzem, o espectador ganha distância para melhor apreciar como estes elementos de significação podem ser apresentados em um espetáculo. A aquisição destes conhecimentos permite que o observador esteja em melhores condições para traçar linhas de reflexão a respeito da obra e elaborar um juízo de valor da mesma.

\footnotetext{
${ }^{4}$ BRECHT apud KOUDELA, Ingrid Dormien. Brecht: um jogo de aprendizagem. São Paulo: Perspectiva, 1991. p. 110.
} 
A distância possibilita que o espectador problematize a encenação, faça perguntas à cena, tais como: Que temas este espetáculo aborda? De que maneira isto se relaciona com a vida lá fora? Que signos e símbolos o artista se utiliza para apresentá-las? Eu já vi algo parecido? Como eu faria? De que outras maneiras esta mesma idéia poderia ser encenada? O prazer de assistir a espetáculos teatrais advém justamente do domínio da linguagem que amplia o interesse pelo teatro na medida em que possibilita uma compreensão mais aguda, uma percepção cada vez mais apurada das encenações.

\section{Procedimentos pedagógicos}

Os procedimentos visando à especialização de espectadores podem ser divididos em: espetaculares e extra-espetaculares. Os primeiros dizem respeito à própria constituição do espetáculo teatral, ou seja, espetáculos criados especialmente com o intuito de formar espectadores especialistas; e aí iremos nos aproximar necessariamente da teoria de teatro épico, criada por Bertolt Brecht. Os procedimentos extra-espetaculares constituem-se, em suma, no fornecimento de material didático sobre a encenação (biografia do autor, proposta de encenação, histórico do grupo, etc.) ou na proposição de jogos e exercícios dramáticos, antes e/ou depois dos espetáculos, com o objetivo de dinamizar a recepção dos espectadores. A seguir, abordaremos mais detalhadamente cada um destes procedimentos pedagógicos.

\section{O teatro épico como prática de formação de espectadores}

Neste breve comentário acerca do caráter formador do teatro épico, em sua vontade de proporcionar a apreensão da linguagem teatral pelos espectadores, será enfatizado especialmente o aspecto narrativo deste teatro brechtiano.

Em suas formulações teóricas com referência a arte teatral, na primeira metade do século XX, Brecht clamava por um teatro que se contrapusesse ao teatro da burguesia, o qual classificava como ilusionista, pois este se valia de algumas técnicas de representação - bem como de algumas inovações científicas da época, em especial a iluminação elétrica. Seu intuito era suscitar, no espectador, a ilusão de estar diante da realidade, como se o artista pretendesse trazer para o palco uma fatia da vida. Impossibilitado de se colocar enquanto sujeito que assiste a uma peça de teatro, o espectador deste teatro burguês, segundo Brecht, seria conduzido emocionalmente pela trama, o que diminuiria a sua capacidade reflexiva.

Os recursos cênicos utilizados pelo teatro épico brechtiano têm, assim, o intuito de afastar o espectador da ação dramática, interrompendo a corrente hipnótica e possibilitando a sua atitude crítica. "O espectador não deve viver o que vivem os personagens, e sim questioná-los"5. O encenador alemão propõe, em seus espetáculos, que o espectador se distancie e reflita sobre o que vê, ao invés de entregar-se a um envolvimento emocional que inviabilizaria o raciocínio. Este efeito de distanciamento é a viga mestra do teatro brechtiano.

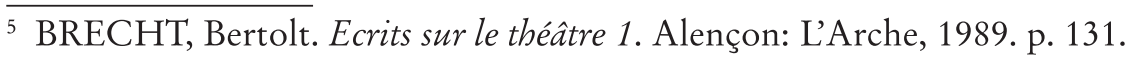


O distanciamento proposto pelo teatro épico brechtiano ao espectador tem nos elementos narrativos trazidos para a encenação seus principais recursos artísticos e pedagógicos.

O épico é um gênero literário em que a história é contada tanto por um narrador, em sua descrição dos acontecimentos, quanto pelos personagens, nos diálogos que interrompem a narrativa. $\mathrm{O}$ épico tem, portanto, um caráter fortemente narrativo, ao contrário do gênero dramático, em que a história vai sendo contada somente por meio do diálogo dos personagens entre si, sem a interferência direta de um narrador (autor).

No gênero épico, o autor relata uma história já ocorrida e, em geral, uma história que aconteceu com uma outra pessoa. Portanto, o narrador fala no pretérito (a história foi assim) e na terceira pessoa do singular (aconteceu com ele). "Isto cria uma certa distância entre o narrador e o mundo narrado" ${ }^{6}$, pois, se a história já aconteceu e aquele que a conta conhece bem todo o seu desenrolar, este narrador não tem o mesmo envolvimento emocional com o fato ocorrido que tem o autor do texto dramático, já que este apresenta o fato no tempo presente, como se o estivesse conhecendo pela primeira vez. Da mesma maneira, o leitor que entra em contato com um texto épico, com uma história já ocorrida, história que lhe é narrada, mantém certa distância do fato e não tem o mesmo envolvimento que o leitor do texto dramático, ao qual os fatos, mesmo quando se trata de um acontecimento histórico, são apresentados como se estivessem acontecendo naquele momento.

O texto no teatro épico, portanto, procura apresentar as situações de forma narrativa, tratando os fatos como históricos - fatos já ocorridos e que têm relevância histórica. Esta distância que se estabelece entre o espectador que assiste no presente a um fato ocorrido no passado permite que ele mantenha uma atitude reflexiva acerca do assunto narrado. No texto do teatro dramático, o autor se ausenta da história, que parece ganhar vida própria; o espectador vivencia a história que acontece diante dele no tempo presente. Vinculado emocionalmente à trama, o espectador do drama teria diminuída a sua capacidade de refletir sobre a mesma.

Como o texto, os elementos cênicos do teatro épico também têm um caráter narrativo. Embora a fábula seja considerada o coração do teatro épico, pois é ela que revela as vicissitudes sociais que enredam os personagens, na concepção brechtiana, no entanto, não apenas o texto, mas a encenação como um todo assume o papel narrativo; o palco conta de maneira crítica a história. Todos os recursos cênicos - a luz, o cenário, os figurinos e adereços - podem desempenhar função narrativa, comentando a ação, tomando posição em face dos acontecimentos. $\mathrm{O}$ palco assume uma função narrativa.

Um dos recursos épicos utilizados por Brecht em suas encenações era, por exemplo, a colocação de grandes telas, em que se projetavam documentos com cifras concretas, ou fotos ou citações, e que permitiam trazer à memória outros processos que se desenrolavam simultaneamente em outros lugares e que contradiziam ou comentavam as palavras e atitudes de alguns personagens.

Esta postura narrativa do palco diante dos fatos trazidos à cena, ressalte-se, somente se tornou viável devido a certas conquistas técnicas do período. A partir de então, para efetivar esta postura, podia-se contar com as projeções de slides e com

\footnotetext{
${ }^{6}$ ROSENFELD, Anatol. O teatro épico. 3. ed. São Paulo: Perspectiva, 1985. p. 25.
} 
os recursos cinematográficos, além de um maquinário motorizado que aumentou as possibilidades de transformação do palco. Estas inovações permitiram ao teatro incorporar estes elementos cenográficos, que davam à encenação um caráter quase literário, com a inclusão na peça de críticas e comentários do autor que, por vezes, assemelhavam-se a notas de pé de página.

A cena começa, assim, a exercer uma função pedagógica. Distante da ação dramática, o espectador do teatro épico pode deparar-se com questões que lhe digam respeito. Assim, o petróleo, a inflação, as lutas sociais, a família, a religião, a manteiga, o pão e o comércio de carnes passam a ser objetos de representação teatral. A intenção era trazer o pano de fundo social para a cena, afirmando a dimensão histórica do acontecimento apresentado por meio dos elementos narrativos que a golpeiam, interrompendo a corrente dramática e afirmando a atitude crítica do espectador. Brecht elaborou uma série de técnicas e recursos cênicos com esta finalidade, entre eles se destacam, por exemplo: jornaleiros que percorrem a sala, anunciando manchetes que caracterizam o clima social, ou slides com fotos históricas, ou ainda canções (songs) e cartazes com dizeres que propunham uma visão crítica sobre o fato representado.

Outro importante aspecto pedagógico deste teatro brechtiano está no fato de que cada elemento da encenação (cenário, figurino, iluminação, etc.) ser apresentado separadamente, e manifestar-se com voz própria em face dos acontecimentos. Assim, ao observarem os elementos da encenação, os espectadores podem perceber a existência, o funcionamento, e a utilização de cada um deles. Isto porque a encenação deixa claro como o artista teatral (diretor, cenógrafo, figurinista, ator, etc.) os está utilizando, possibilitando que o espectador perceba que, se a cena é assim apresentada, ela poderia também ser concebida de outras maneiras; e que as construções da encenação são sempre opções do artista, que se apresenta enquanto autor do espetáculo e assume uma posição em face da história que apresenta. Ao se tornar conhecedor da utilização dos diversos elementos que compõem uma encenação, e atento para a dimensão histórica dos fatos, o espectador do teatro épico se torna um especialista, apto a compreender criticamente as cenas apresentadas no palco, e estimulado a produzir sentidos próprios para os acontecimentos históricos.

\section{Dinamizando a recepção teatral}

A expansão das práticas extra-espetaculares de formação de espectadores se dá especialmente nos anos 1960, na esteira dos movimentos contraculturais que clamavam pela democratização da arte teatral, e que, entre outras tantas conquistas, propuseram o estreitamento das relações entre teatro e escola. Artistas e educadores passam, a partir de então, a propor às escolas, com maior freqüência, diversas atividades de expressão dramática, com o objetivo de sensibilizar crianças e jovens para o teatro. Dentre estas práticas, que passaram a ser conceituadas como animações teatrais, estão as que se organizavam em torno de um espetáculo teatral, dinamizando a compreensão da encenação vista pelos alunos.

Estas práticas de formação de espectadores podem dividir-se em dois aspectos, principalmente: os procedimentos pedagógicos de integração escolar e os procedimentos pedagógicos de leitura. 
Os procedimentos pedagógicos de integração escolar, como o próprio termo sugere, buscam integrar a obra teatral ao processo de aprendizagem escolar. O espetáculo motiva atividades variadas, torna-se o pivô de um estudo que pode interligar diversas disciplinas do currículo escolar, sendo utilizado como atividade de reforço. A peça propicia, assim, a aplicação de exercícios, visando a uma dinamização do aprendizado em múltiplas áreas do conhecimento.

Os procedimentos pedagógicos de integração escolar acontecem, por via de regra, após o espetáculo e estabelecem relações entre a encenação vista pelos alunos e as diversas áreas do conhecimento. As atividades de desdobramento da peça enfocam, por exemplo: noções de matemática (exercícios de conjunto, os personagens são em grupos); abordagens históricas; exercícios de expressão escrita (redações sobre a peça ou aplicação de ditados); atividades de artes plásticas (a criação de cartazes para a peça ou de desenhos animados que retratassem a história contada). Entre outras tantas atividades que variavam em função das possíveis abordagens suscitadas pelo espetáculo e da faixa etária dos alunos.

Estas práticas de prolongamento de um espetáculo, visando à integração da arte ao currículo da escola, têm sido muito criticadas, acusadas de "pedagogizar" o teatro pelo fato do espetáculo ser utilizado como instrumento de aprendizagem de determinadas disciplinas da grade curricular ou como mero pretexto para atividades normalmente aplicadas no cotidiano escolar. A arte teatral acaba, deste modo, por ser "fagocitada" pelo sistema de ensino. Considera-se que a utilização do teatro como ferramenta para a apreensão de conteúdos disciplinares empobrece o diálogo do aluno-espectador (e os desdobramentos deste diálogo) com a peça, e torna a experiência estética padronizada, ao atrelar a recepção às necessidades imediatas da escola.

Os procedimentos pedagógicos de leitura podem ser divididos em borizontal e transversal. Nos procedimentos de leitura horizontal, o conteúdo da peça é prioritariamente abordado nos exercícios propostos. Os artistas e educadores estimulam o grupo de alunos a debater o assunto em questão e a improvisar cenas que se relacionem com o tema da peça. Estas práticas chamam a atenção dos participantes para o discurso da obra, para a atualidade dos temas tratados, além de provocar a observação dos espectadores para como a encenação lida com tais questões e que técnicas teatrais são utilizadas nesta abordagem.

Estes prolongamentos, que enfocam primordialmente a temática da peça, podem, por exemplo, ser estruturados a partir das seguintes atividades: 1) exposição prévia sobre a vida do autor, de seu tempo (em se tratando de uma peça de época) e do conteúdo do texto; 2 ) debates posteriores ao espetáculo abordando a atualidade das situações encenadas; 3) proposição de exercícios dramáticos em que os alunos transpõem cenas da peça para acontecimentos contemporâneos ou mesmo para situações outras que, de algum modo, estejam relacionadas àquelas apresentadas pelos atores.

Nos procedimentos pedagógicos de leitura transversal, que têm como objetivo estimular os alunos-espectadores para o reconhecimento, a decodificação, a interpretação dos signos do espetáculo e o enfoque dado às atividades propostas reduzem a importância da percepção imediata provocando o espectador a empreender uma análise detalhada da encenação, estimulando-o a efetivar a sua compreensão 
dos significados contidos nas concepções dramatúrgicas, nas intenções gestuais, nas opções cenográficas e nas demais criações dos realizadores do espetáculo. Propiciar aos alunos a compreensão do espetáculo não se reduz, assim, à trama, mas se constitui de uma totalidade de signos, pois se possibilita a percepção da especificidade da arte teatral e a elaboração dos elementos semióticos presentes na encenação. Estas práticas são fundamentalmente implementadas a partir de companhias teatrais que constroem os seus espetáculos tendo em vista a busca de uma escritura cênica provocativa, nem sempre evidente, que valoriza a atitude do espectador diante da obra, incitando-o a engendrar uma leitura própria, inventiva dos signos propostos.

Partindo do princípio de que a capacidade de ler os signos não é um fenômeno natural, mas uma conquista cultural, estes procedimentos pedagógicos de leitura teatral têm o intuito de estimular e sensibilizar os espectadores para a decifração dos códigos e a efetivação de uma leitura plural do espetáculo. 


\section{REFERÊNCIAS}

BAKHTIN, Mikhail. Estética da criação verbal. São Paulo: M. Fontes, 1992.

BENJAMIN, Walter. Obras escolbidas: magia e técnica, arte e política. 2. ed. São Paulo: Brasiliense, 1993.

BORNHEIM, Gerd. Brecht, a estética do teatro. Rio de Janeiro: Graal. 1992.

BRECHT, Bertolt. Ecrits sur le théâtre 1. Alençon: L'Arche, 1989.

DEBORD, Guy. La société du spectacle. 2. ed. Paris: Gallimard, 1992.

DELDIME, Roger; PIGEON, Jeane. La mémoire du jeune spectateur. Bruxelas: De Boeck, 1988.

DESGRANGES, Flávio. A pedagogia do espectador. São Paulo: Hucitec, 2003.

DESGRANGES, Flávio. Pedagogia do Teatro: provocação e dialogismo. São Paulo: Hucitec, 2006.

KOUDELA, Ingrid Dormien. Brecht: um jogo de aprendizagem. São Paulo: Perspectiva, 1991.

ROSENFELD, Anatol. O teatro épico. 3. ed. São Paulo: Perspectiva, 1985. 